\title{
FORMULATION DEVELOPMENT AND EVALUATION OF CHRONOMODULATED DRUG DELIVERY SYSTEM BY ZAFIRLUKAST
}

\section{N. SHIVA KRISHNA ${ }^{1}{ }^{*}$, B. JAYANTHI ${ }^{2}$, A. MADHUKAR ${ }^{3}$}

${ }^{1}$ Department of Pharmaceutics, St Marys Group of Institutions, Deshmukhi (V) Pochampally and Batasingaram (M) Near Ramoji Film City Hayathnagar (M) Ranga Reddy (Dist.) 508284, Hyderabad, Telangana, India, 2Department of Pharmaceutics (Drug Delivery System), Annamalai University, Annamalainagar 608002, Tamil Nadu, India, ${ }^{3}$ Department of Pharmacy, MRM College of Pharmacy, Chinthapalliguda, Ibrahimpatnam, Hyderabad 501510, Telangana, India

Email: shivakrishnapharmacy@gmail.com

Received: 08 Apr 2021, Revised and Accepted: 27 May 2021

\section{ABSTRACT}

Objective: The main objective of the present study was to formulate and evaluate a time-controlled single-unit oral pulsatile drug delivery system containing Zafirlukast for the prevention of nocturnal asthma attacks. To provide time-scheduled drug release for Asthma disease. It is used for preventing asthmatic attacks at early morning. Pulsatile release dosage form is increasing patient compliance by reducing the dosing frequency, especially in the early morning.

Methods: Core tablets were prepared by incorporating different concentrations of natural and synthetic super disintegrants. Drug-containing core tablets (ZC1-ZC15) with different compositions of natural super disintegrants (Plantago ovata seed powder, Locust bean gum) synthetic super disintegrants (Sodium starch glycolate (SSG), Cross carmellose sodium (CCS), Crospovidone (CP)) were prepared by direct compression technique. The core tablets were subjected to pre-formulation, physicochemical and In vitro drug release studies. The fast disintegrating core tablet formulation was selected and press-coated tablets (P1-P11) were prepared with different compositions of hydrophobic polymers Eudragit RS100, Eudragit RL 100, Ethylcellulose and hydrophilic polymers Hydroxypropyl methylcellulose K4M, K100M. The optimized formulation was selected and quantified based on in vitro drug release profile in simulated gastric and intestinal fluids.

Results: The pre and post-compression parameters of tablets were also found to be within limits. Formulation ZC5 with 16 mg of Locust bean gum showed the least disintegrating time, i.e., $22.13 \mathrm{sec}$, and was selected as the best immediate release core tablet. The press-coated tablet formulation P8 having $62.5 \mathrm{mg}$ Eudragit RS100 and $62.5 \mathrm{mg}$ of HPMC K4M in ratio 1:1 over the core tablet ZC5 showed rapid and drug release nearly after $4 \mathrm{~h}$ lag time and $98.86 \%$ up to $12 \mathrm{~h}$. Accelerated stability studies of the optimized formulation P8 indicated no significant difference in release profile after 3 mo.

Conclusion: The in vitro dissolution study showed that lag time before drug release was highly affected by the coating amount level and nature of coating polymer used. Time-controlled pulsatile release tablets can be prepared using press-coating techniques.

Keywords: Pulsatile formulation, Zafirlukast, Chronomodulated drug delivery system, Compression coated tablets

(c) 2021 The Authors. Published by Innovare Academic Sciences Pvt Ltd. This is an open access article under the CC BY license (https://creativecommons.org/licenses/by/4.0/) DOI: https://dx.doi.org/10.22159/ijap.2021v13i4.41734. Journal homepage: https://innovareacademics.in/journals/index.php/ijap

\section{INTRODUCTION}

The time-controlled and pulsatile release is increasingly being considered as desirable modes of drug delivery [1-3]. A pulsatile drug delivery system (PDDS) can be dfined as a system where the drug is released suddenly after a well-defined lag time according to the circadian rhythm of the disease $[4,5]$. PDDS can be clasfiied according to the pulse-regulation of drug release into three main classes; time-controlled pulsatile release (single or multiple unit system), internal stimuli-induced release, and external stimuliinduced pulsatile release systems [4, 6]. PDDS can also be classfied according to the dosage form into three main types; capsules, pellets, and tablets. The tablet system consists of two different core tablets, containing the active ingredient, the outer top cover layer of a soluble polymer, and insoluble polymer [4, 7]. The release of some drugs is preferred in pulses. A single dosage form provides an initial dose of the drug followed by one release-free interval, after which a second dose of the drug is released, which is followed by an additional release-free interval and pulse of drug release [8].

Depending upon the physiological and physiopathological changes of circadian rhythmicity, nocturnal symptoms and overnight decrements in lung functions are a common part of the asthma clinical syndrome [9]. Circadian changes are seen in normal lung function, which reaches a low point in the early morning hours. The dip is particularly pronounced in people with asthma, because bronchoconstriction and exacerbation of symptoms vary in a circadian fashion, a sharp increase in asthmatic attacks during early morning hours. For such conditions a drug delivery system administered at bedtime, but releasing the drug during morning hours, would be an ideal one [10].
The main objective of the study was to develop a time-controlled release formulation based on a press coat technique using ratecontrolling natural (hydrophilic) polymers and synthetic (hydrophobic) polymers and Zafirlukast as a model drug. The intention was to maintain lag time 3-4 h. As the symptoms of asthma are experienced in the early morning hours. The incorporation of the drug as an immediate release formulation in the core is proposed to provide the drug to the patient at the right time of asthmatic risk. The release is expected as a burst, i. e at once pulsatile drug delivery of Zafirlukast after a lag time [11-13]. The rationale for the development of an appropriate formulation is to provide the drug at the right time, i.e. early morning. The formulation has a rapidrelease core tablet of Zafirlukast with super disintegrants [14].

\section{MATERIALS AND METHODS}

\section{Materials}

Zafirlukast was Provided by Sura Labs, Dilsukhnagar. Plantago ovata seed powder was Purchased from the local market. Sodium starch glycolate Purchased from SD Fine Chemicals, Mumbai. Crospovidone, Locust bean gum, and Croscarmellose sodium were Purchased from R. K. Enterprises, Ghaziabad. Eudragit RS100 was Purchased from Evonik Industries, Mumbai, Maharashtra. Eudragit RL 100 was Purchased from Evonik Industries, Mumbai, Maharashtra. Ethylcellulose was Purchased from CDH chemicals, New Delhi, India. HPMC K4M and HPMC K100M were Purchased from Colorcon Asia Pvt. Ltd., Goa. Mannitol, Mg Stearate, Talc, and PVP K 30 were purchased from SD Fine Chemicals. Mumbai, Maharashtra. Aerosil was purchased from Reachem labs, New Delhi, India. MCC was purchased from Sigma Chemicals, Bangalore, India. 


\section{Methods}

\section{Formulation development of tablets}

\section{Formulation of core tablets by direct compression}

The inner core tablets were prepared by using the direct compression method [15] as shown in the table. Powder mixtures zafirlukast, Plantago ovata seed powder, Locust bean gum, Sodium starch glycolate, Crospovidone, CCS, talc ingredients were blended for $20 \mathrm{~min}$ followed by the addition of Magnesium stearate. The mixtures were then further blended for $10 \mathrm{~min}$ [16]., $50 \mathrm{mg}$ of resultant powder blend was manually compressed using, Lab press Limited, India with a $6 \mathrm{~mm}$ punch and die to obtain the core tablet (table).

\section{Formulation of a mixed blend for the barrier layer}

The various formulation compositions containing Ethyl Cellulose, Eudragit RS100, Eudragit RL 100, HPMC K4M, HPMC K100, magnesium stearate, talc, and microcrystalline cellulose. Different compositions were weighed processed using the wet granulation Technique and used as a press coating material to prepare presscoated pulsatile tablets respectively by wet granulation Technique (table).

\section{Preparation of press-coated tablets}

The core tablets were press-coated with $300 \mathrm{mg}$ of the mixed blend as given in Table. $200 \mathrm{mg}$ of barrier layer material was weighed and transferred into a $10 \mathrm{~mm}$ die then the core tablet was placed manually at the center and compressed by using Lab press Limited, India [17].

\section{Optimization of core tablets}

For optimization of core tablets, various formulations were prepared as noted in a table.

Table 1: Formulation development of core tablets

\begin{tabular}{|c|c|c|c|c|c|c|c|c|c|c|c|c|c|c|c|}
\hline Ingredients (mg) & ZC1 & ZC2 & ZC3 & ZC4 & ZC5 & ZC6 & ZC7 & ZC8 & ZC9 & ZC10 & ZC11 & ZC12 & ZC13 & ZC14 & ZC15 \\
\hline \multicolumn{16}{|c|}{ Core tablet formulation blend } \\
\hline Zafirlukast & 20 & 20 & 20 & 20 & 20 & 20 & 20 & 20 & 20 & 20 & 20 & 20 & 20 & 20 & 20 \\
\hline $\begin{array}{l}\text { Plantago ovata seed } \\
\text { powder }\end{array}$ & 8 & 16 & 24 & - & - & - & - & - & - & - & - & - & - & - & - \\
\hline Locust bean gum & - & - & - & 8 & 16 & 24 & - & - & - & - & - & - & - & - & - \\
\hline $\begin{array}{l}\text { Sodium starch glycolate } \\
\text { (SSG) }\end{array}$ & - & - & - & - & - & - & 8 & 16 & 24 & - & - & - & - & - & - \\
\hline $\begin{array}{l}\text { Cross carmellose } \\
\text { sodium }(\mathrm{CCS})\end{array}$ & - & - & - & - & - & - & - & - & - & 8 & 16 & 24 & - & - & - \\
\hline Crospovidone (CP) & - & - & - & - & - & - & - & - & - & - & - & - & 8 & 16 & 24 \\
\hline Aerosil & 1 & 1 & 1 & 1 & 1 & 1 & 1 & 1 & 1 & 1 & 1 & 1 & 1 & 1 & 1 \\
\hline $\begin{array}{l}\text { Sodium stearyl } \\
\text { fumerate (SSF) }\end{array}$ & 3 & 3 & 3 & 3 & 3 & 3 & 3 & 3 & 3 & 3 & 3 & 3 & 3 & 3 & 3 \\
\hline Mannitol & Q. S & Q.S & Q.S & Q.S & Q. S & Q.S & Q. S & Q. S & Q.S & Q.S & Q.S & Q. S & Q.S & Q.S & Q. S \\
\hline Total Weight & 150 & 150 & 150 & 150 & 150 & 150 & 150 & 150 & 150 & 150 & 150 & 150 & 150 & 150 & 150 \\
\hline
\end{tabular}

Table 2: Formulations for press coated blend

\begin{tabular}{|c|c|c|c|c|c|c|c|c|c|c|c|}
\hline Ingredients (mg) & P1 & $\mathbf{P 2}$ & P3 & P4 & P5 & P6 & P7 & P8 & P9 & P10 & P11 \\
\hline $\begin{array}{l}\text { Optimized formulation core tablets (Total weight-150 mg) } \\
\text { Coated formulation blend }\end{array}$ & $\mathrm{ZC}^{*}$ & $\mathrm{ZC}^{*}$ & $\mathrm{ZC}^{*}$ & $\mathrm{ZC}^{*}$ & $\mathrm{ZC}^{*}$ & $\mathrm{ZC}^{*}$ & $\mathrm{ZC}^{*}$ & $\mathrm{ZC}^{*}$ & $\mathrm{ZC}^{*}$ & $\mathrm{ZC}^{*}$ & $\mathrm{ZC}^{*}$ \\
\hline Ethyl Cellulose & 62.5 & - & - & - & - & 62.5 & - & - & 62.5 & - & - \\
\hline Eudragit RL 100 & - & 62.5 & - & - & - & - & 62.5 & - & - & 62.5 & - \\
\hline Eudragit RS100 & - & - & 62.5 & - & - & - & - & 62.5 & - & - & 62.5 \\
\hline HPMC K4M & - & - & - & 62.5 & - & 62.5 & 62.5 & 62.5 & - & - & - \\
\hline HPMC K100M & - & - & - & - & 62.5 & - & - & - & 62.5 & 62.5 & 62.5 \\
\hline PVP K30 & 6.5 & 6.5 & 6.5 & 6.5 & 6.5 & 6.5 & 6.5 & 6.5 & 6.5 & 6.5 & 6.5 \\
\hline IPA (Iso Propyl Alcohol) & QS & QS & QS & QS & QS & QS & QS & QS & QS & QS & QS \\
\hline Mg. Stearate & 4 & 4 & 4 & 4 & 4 & 4 & 4 & 4 & 4 & 4 & 4 \\
\hline Talc & 2 & 2 & 2 & 2 & 2 & 2 & 2 & 2 & 2 & 2 & 2 \\
\hline MCC & 125 & 125 & 125 & 125 & 125 & 62.5 & 62.5 & 62.5 & 62.5 & 62.5 & 62.5 \\
\hline Total weight of Press coated blend & 200 & 200 & 200 & 200 & 200 & 200 & 200 & 200 & 200 & 200 & 200 \\
\hline Total weight of Press coated tablet & 350 & 350 & 350 & 350 & 350 & 350 & 350 & 350 & 350 & 350 & 350 \\
\hline
\end{tabular}

*ZC optimized core formulation

\section{Formulation of press coated blend}

These ingredients are used in the preparation of different chronomodulated drug delivery system formulation grannules.

\section{Evaluations}

\section{Post compression parameters of core and press coated tablets}

The tablets after punching of every batch were evaluated for inprocess and finished product quality control tests i.e. thickness, weight uniformity test, hardness, friability, drug content, and in vitro drug release studies [18].

\section{Hardness}

The prepared tablets were subjected to a hardness test. It was carried out by using Monsanto, Mumbai, India, and expressed in $\mathrm{Kg} / \mathrm{cm}^{2}$ [19].

\section{Thickness}

The prepared tablets were subjected to a thickness test. It was carried out by using the vernier caliper Mitutoyo, Japan [20] and expressed in millimeters.

\section{Friability test}

The friability was determined using the friability test apparatus Labindia, Mumbai, India, and expressed in percentage (\%). 20 tablets from each batch were weighed separately ( $\mathrm{W}$ initial) and placed in the friabilator, which was then operated for 100 revolutions at $25 \mathrm{rpm}$ [21]. The tablets were reweighed (W final) and the percentage friability was calculated for each batch by using the following formula [22].

$$
\text { Friability }=[(W 1-W 2) / W 1] * 100
$$


Where,

W1 = Initial weight of three tablets

W2 = Weight of the three tablets after testing

\section{Weight variation test}

Twenty tablets were selected at random from the lot, weighed individually and the average weight was determined [23]. The percent deviation of each tablet's weight against the average weight was calculated. The test requirements are met if not more than two of the individual weights deviate from the average weight by more than $5 \%$.

\section{Drug content}

The Zafirlukast tablets were tested for their drug content. Ten tablets were finely powdered [24]. The required quantities of the powder equivalent to $20 \mathrm{mg}$ of Zafirlukast were accurately weighed and transferred to a $100-\mathrm{mL}$ of volumetric flask [25]. The flask was filled with buffer and mixed thoroughly. The solution was made up of Volume and filtered. Dilute $1 \mathrm{ml}$ of the resulting solution to $100 \mathrm{ml}$ with media and measure the absorbance of the resulting solution at the maximum at $238 \mathrm{~nm}$ using a UV spectrophotometer (Labindia, Mumbai, India). The linearity equation obtained from the calibration curve as described previously was used for the estimation of Zafirlukast in the tablets formulations.

\section{Disintegration time of core tablets}

A disintegration test was carried out using the tablet disintegration test apparatus specified in Indian pharmacopeia. $\mathrm{pH} 6.8$ phosphate buffer at $37 \pm 2{ }^{\circ} \mathrm{C}$ was used as the disintegration media and the time in second taken for complete disintegration of the tablet with no palpable mass remaining on the screen was measured in seconds [26].

\section{In vitro drug release study of pulsatile zafirlukast tablets}

\section{In vitro drug release of Zafirlukast core tablets}

In vitro dissolution studies were carried out using the USP XXIII Type II (paddle method) apparatus. pH 6.8 phosphate buffer was used as a dissolution medium. Release pattern was studied visually by taking a sample of $5 \mathrm{ml}$ at specific time intervals. Also, the sample was analyzed at $238 \mathrm{~nm}$ for 6.8 phosphate buffer using a UV spectrophotometer [27].

\section{In vitro drug release study of coated tablets}

$900 \mathrm{ml}$ 0f $0.1 \mathrm{HCL}$ was placed in a vessel and the USP apparatus-II (Paddle Method) was assembled. The medium was allowed to equilibrate to the temp of $37{ }^{\circ} \mathrm{c}+0.5{ }^{\circ} \mathrm{c}$. Tablet was placed in the vessel and apparatus was operated for $2 \mathrm{~h}$ and then the media $0.1 \mathrm{~N}$ HCL were removed and $\mathrm{pH} 6.8,7.4$ phosphate buffer was added process was continued up to $12 \mathrm{~h}$ at $50 \mathrm{rpm}$. A definite time interval was withdrawn $5 \mathrm{ml}$ of sample, filtered, and again $5 \mathrm{ml}$ media was replaced. Suitable dilutions were done with media and analyzed by spectrophotometrically at respective wavelengths using UVspectrophotometer [28].

\section{Application of release rate kinetics to dissolution data}

Various models were tested for explaining the kinetics of drug release. To analyze the mechanism of the drug release rate kinetics of the dosage form, the obtained data were fitted into zero-order, first-order, Higuchi, and Korsmeyer-Peppas release model [29, 30].

\section{Zero-order release rate kinetics}

To study the release kinetics, the release rate data are fitted to the following equation.

$$
F=K 0 t
$$

Where, ' $\mathrm{F}$ ' is the drug release at time ' $\mathrm{t}$ ', and ' $\mathrm{KO}$ ' is the zero-order release rate constant. The plot of $\%$ drug release versus time is linear.

\section{First-order release rate kinetics}

The release rate data are fitted to the following equation.

$$
\log (100-F)=k t
$$

A plot of log cumulative percent of drug remaining to be released vs. time is plotted then it gives the first-order release.

\section{Higuchi release model}

To study the Higuchi release kinetics, the release rate data were fitted to the following equation.

$$
F=k t 1 / 2
$$

Where ' $k$ ' is the Higuchi constant.

In the Higuchi model, a plot of \% drug release versus the square root of time is linear.

\section{Korsmeyer and peppas release model}

The mechanism of drug release was evaluated by plotting the log percentage of drug released versus log time according to the Korsmeyer-Peppas equation. The exponent ' $n$ ' indicates the mechanism of drug release calculated through the slope of the straight Line.

$$
M t / M \alpha=K t n
$$

Where, $M t / M \propto$ is a fraction of drug released at a time ' $t$ ', $k$ represents a constant, and ' $n$ ' is the diffusional exponent, which characterizes the type of release mechanism during the dissolution process. For non-Fickian release, the value of $n$ falls between 0.5 and 1.0; while in the case of Fickian diffusion, $\mathrm{n}=0.5$; for zero-order release (case II transport), $n=1$; and for super case II transport, $n>1$. In this model, a plot of $\log (\mathrm{Mt} / \mathrm{M} \infty)$ versus $\log$ (time) is linear [31].

\section{Stability studies}

For the determination of stability of prepared different formulations, accelerated stability studies were carried out on optimized formulation. Tablets were stored according to ICH guidelines at $40 \pm 2{ }^{\circ} \mathrm{C} / 75 \pm 5 \%$ RH for three months by storing the samples in (Labcare, Mumbai) stability chamber. After completion of the required duration time, the sample was withdrawn and tested for different tests such as hardness, drug content, and in vitro drug release [32].

\section{In vivo studies-pharmacokinetic studies}

To investigate the peak plasma concentration pharmacokinetic studies were carried out. The In vivo studies were conducted on Wistar male rats weighing 250-300 gm. They were housed in polypropylene cages and had free access to food and water. The dose of zafirlukast was calculated as per the bodyweight of animals and developed tablets were formulated considering the calculated dose. The animal protocol was approved by the Institutional Animals Ethical Committee. The optimized pulsatile tablets were administered orally. Blood samples were collected for over $24 \mathrm{~h}$ according to a predetermined sample collection schedule. Various pharmacokinetic parameters like $\mathrm{C}_{\max }, \mathrm{T}_{\max }, \mathrm{AUC}$ were determined [33].

\section{RESULTS AND DISCUSSION}

In the present work, Zafirlukast is an Anti-inflammatory, leukotriene receptor antagonist (LTRAs) drug used in the treatment of asthma and prevent asthma attacks [34]. An attempt has been made to improve the bioavailability Present is in the form of a chronomodulated drug delivery system to provide a controlled release for a prolonged period of time.

\section{Preformulation studies}

Table 3: Physical properties of drug

\begin{tabular}{lll}
\hline S. No. & Parameter & Drug zafirlukast \\
\hline 1. & Colour & White \\
2. & Odour & Odourless \\
3. & Taste & tasteless \\
4. & Appearance & Amorphous powder \\
\hline
\end{tabular}


Melting point

Table 4: Melting point determination of drug

\begin{tabular}{lll}
\hline Drug name & Reported melting point & observed melting point \\
\hline Zafirlukast & 138 to $140^{\circ} \mathrm{C}$ & $139-141^{\circ} \mathrm{C}$ \\
\hline
\end{tabular}

The melting point was determined by the capillary tube method and it was found to be $139-141{ }^{\circ} \mathrm{C}$ Zafirlukast by taking the averages of 3 consecutive readings. This value is the same as that of the literature citation shown in table.

\section{Solubility studies}

Table 5: Solubility studies of drug

\begin{tabular}{lll}
\hline Medium & $\begin{array}{l}\text { Ratio (drug: solvent) for } \\
\text { zafirlukast }\end{array}$ & $\mathbf{m g} \mathbf{1 0 0} \mathbf{~ m l}$ \\
\hline Water & $1: 4$ & Insoluble \\
Methanol & $1: 3$ & Slightly soluble \\
0.1N HCL & $1: 5$ & Slightly soluble \\
Phosphate buffer & $1: 3$ & Slightly soluble \\
pH(6.8) & & \\
\hline
\end{tabular}

The solubility of Zafirlukast was determined in different solvent systems. The maximum solubility was found in $0.1 \mathrm{~N} \mathrm{HCL}$ and water.

\section{FTIR}

\section{Drug-excipient compatibility}

Table 6: Peaks observed in pure drug and optimized formulation

\begin{tabular}{llll}
\hline Functional groups & Wavenumber in cm-1 & Pure drug & Optimized formulation \\
\hline C-H Bending & $2960-2850$ & 2952.26 & 2952.62 \\
C=C Stretch & 990 & 990.86 & 990.84 \\
C=O Stretching & $1730-1700$ & 1723.63 & 1723.41 \\
C-H Stretch & $2960-2850$ & 2870.87 & 2871.14 \\
O-H Stretching & $3600-3200$ or3650 & 3544.94 & 3542.83 \\
N-H Stretch & $3700-3500$ & 3544.94 & 3542.83 \\
Benzene ring & $1660-2000$ & 1696.65 & 1696.50 \\
C-O & $1210-1320$ & 1225.70 & 1225.52 \\
Aromatic C-H stretch & $3020-3000$ & 3010.50 & 3010.91 \\
SO & 1374 & 1368.48 & 1368.16 \\
\hline
\end{tabular}

From the above table, it was showed no interactions between drug and excipients. Both API and excipients compatibility with each other.

\section{Differential scanning calorimetry (DSC)}

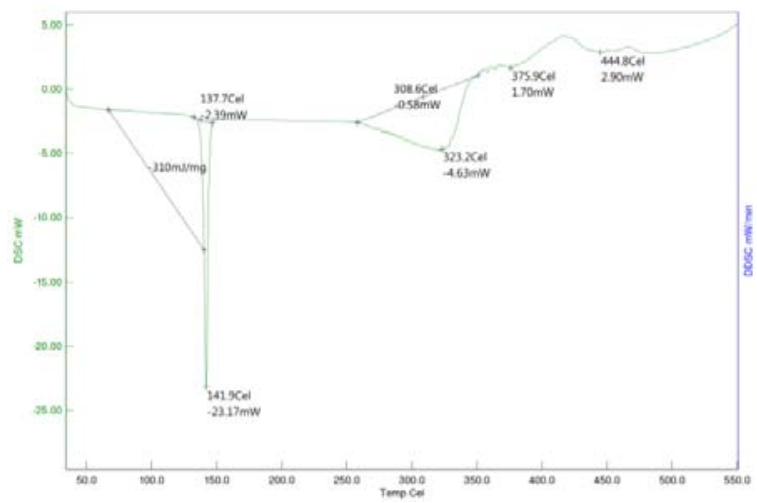

Fig. 1: DSC graph of zafirlukast pure drug

The DSC spectrum of pure Zafirlukast showed a sharp endothermic peak at $141.9{ }^{\circ} \mathrm{C}$ and it was the melting point of the drug. The mixture of Zafirlukast and polymers shows doesn't change the thermal behavior of the sharp endothermic peak of the drug at 138.0 ${ }^{\circ} \mathrm{C}$. It indicated that there was no interaction between the drug and polymers. These results revealed that the drug was stable at higher temperatures and neither drug decomposition nor drug-excipients interactions occurred in the prepared chronomodulated drug delivery system [35].

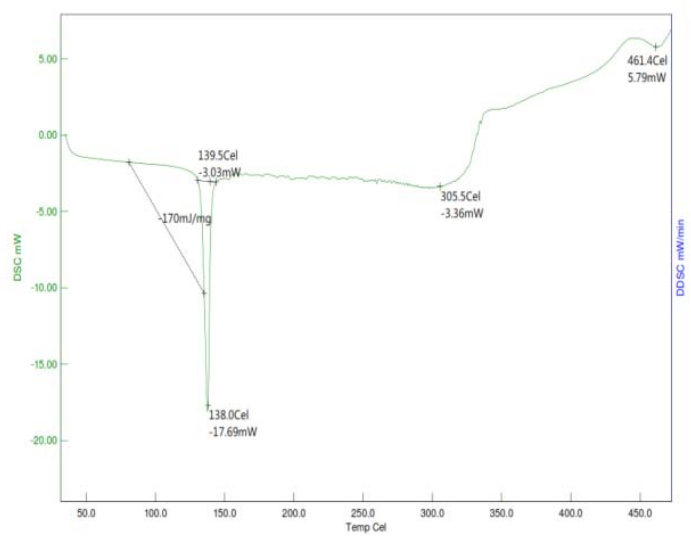

Fig. 2: DSC graph of zafirlukast optimized formulation

\section{Calibration curve}

Graphs of Zafirlukast were taken in 0.1 N HCL, phosphate buffer pH 6.8, 7.4.

Table 7: Calibration curve data for zafirlukast

\begin{tabular}{llll}
\hline Concentrations $[\boldsymbol{\mu g} / \mathbf{m l}]$ & Absorbance in 0.1N HCL at 235 nm & $\begin{array}{l}\text { Absorbance in phosphate buffer pH 6.8 } \\
\text { at 239 } \mathbf{~ m ~}\end{array}$ & $\begin{array}{l}\text { Phosphate buffer pH 7.4 at } \\
\mathbf{2 3 9} \mathbf{~ n m}\end{array}$ \\
\hline 0 & & 0 & 0 \\
5 & 0 & 0.185 & 0.183 \\
10 & 0.114 & 0.358 & 0.388 \\
15 & 0.225 & 0.598 & 0.595 \\
20 & 0.312 & 0.784 & 0.801 \\
25 & 0.411 & 0.989 & 0.959 \\
\hline
\end{tabular}

The standard graph of Zafirlukast showed good linearity, which indicates that it obeys the "Beer-Lamberts" law [36]. 
Table 8: Pre-formulation parameters of blend

\begin{tabular}{|c|c|c|c|c|c|}
\hline Formulation code & Angle of repose $(\theta)$ & Bulk density (gm/ml) & Tapped density (gm/ml) & Carr's index (\%) & Hausner's ratio \\
\hline $\mathrm{ZC1}$ & $23.98 \pm 1.2$ & $0.549 \pm 0.01$ & $0.626 \pm 0.01$ & $12.30 \pm 0.13$ & $1.140 \pm 0.02$ \\
\hline $\mathrm{ZC} 2$ & $28.72 \pm 2.5$ & $0.335 \pm 0.03$ & $0.470 \pm 0.05$ & $28.72 \pm 0.12$ & $1.401 \pm 0.01$ \\
\hline $\mathrm{ZC} 3$ & $21.12 \pm 2.5$ & $0.409 \pm 0.02$ & $0.531 \pm 0.06$ & $22.97 \pm 0.13$ & $1.298 \pm 0.06$ \\
\hline ZC4 & $26.89 \pm 0.5$ & $0.681 \pm 0.03$ & $0.887 \pm 0.05$ & $23.22 \pm 0.18$ & $0.980 \pm 0.01$ \\
\hline ZC5 & $24.19 \pm 0.5$ & $0.547 \pm 0.06$ & $0.624 \pm 0.04$ & $12.33 \pm 0.11$ & $1.140 \pm 0.03$ \\
\hline ZC6 & $26.6 \pm 0.6$ & $0.555 \pm 0.03$ & $0.714 \pm 0.07$ & $22.22 \pm 0.21$ & $1.280 \pm 0.06$ \\
\hline ZC7 & $22.67 \pm 0.8$ & $0.395 \pm 0.01$ & $0.475 \pm 0.01$ & $20.25 \pm 0.17$ & $1.202 \pm 0.03$ \\
\hline ZC8 & $26.02 \pm 0.8$ & $0.267 \pm 0.03$ & $0.307 \pm 0.03$ & $13.33 \pm 0.18$ & $1.150 \pm 0.06$ \\
\hline ZC9 & $27.67 \pm 1.0$ & $0.429 \pm 0.03$ & $0.546 \pm 0.05$ & $23.93 \pm 0.19$ & $1.272 \pm 0.03$ \\
\hline $\mathrm{ZC} 10$ & $26.02 \pm 1.2$ & $0.267 \pm 0.01$ & $0.307 \pm 0.08$ & $13.33 \pm 0.12$ & $1.150 \pm 0.01$ \\
\hline ZC11 & $24.70 \pm 0.4$ & $0.519 \pm 0.04$ & $0.683 \pm 0.08$ & $13.46 \pm 0.13$ & $1.315 \pm 0.03$ \\
\hline ZC12 & $25.81 \pm 0.8$ & $0.393 \pm 0.06$ & $0.453 \pm 0.09$ & $13.24 \pm 0.14$ & $1.150 \pm 0.02$ \\
\hline ZC13 & $25.31 \pm 2.2$ & $0.330 \pm 0.07$ & $0.380 \pm 0.05$ & $13.15 \pm 0.15$ & $1.152 \pm 0.04$ \\
\hline ZC14 & $24.70 \pm 1.4$ & $0.462 \pm 0.09$ & $0.591 \pm 0.06$ & $21.82 \pm 0.13$ & $1.279 \pm 0.06$ \\
\hline ZC15 & $26.31 \pm 1.2$ & $0.232 \pm 0.05$ & $0.273 \pm 0.07$ & $15.52 \pm 0.12$ & $1.181 \pm 0.01$ \\
\hline
\end{tabular}

Each value represents the mean $\pm \operatorname{SD}(n=3)$

Tablet powder blend was subjected to various pre-formulation parameters. The angle of repose values indicates that the powder blend has good flow properties. The bulk density of all the formulations was found to be in the range of $0.232 \pm 0.05$ to $0.681 \pm 0.03(\mathrm{gm} / \mathrm{ml})$ showing that the powder has good flow properties. The tapped density of all the formulations was found to be in the range of $0.273 \pm 0.07$ to $0.683 \pm 0.08$ showing the powder has good flow properties. The compressibility index of all the formulations was found to be below $28.72 \pm 2.5$ which shows that the powder has good flow properties. All the formulations have shown the Hausner's ratio ranging between 0 to $1.401 \pm 0.01$ indicating the powder has good flow properties [37].

\section{Quality control parameters for tablets}

Tablet quality control tests such as weight variation, hardness, and friability, thickness, Drug content, and drug release studies were performed for core tablets.

Table 9: In vitro quality control parameters for core tablets

\begin{tabular}{|c|c|c|c|c|c|}
\hline Formulation codes & Average weight (mg) & Hardness $\left(\mathrm{Kg} / \mathrm{cm}^{2}\right)$ & Friability (\% loss) & Thickness (mm) & Drug content (\%) \\
\hline $\mathrm{ZC1}$ & $150.5 \pm 1$ & $4.5 \pm 0.8$ & 0.52 & $3.5 \pm 0.01$ & $99.76 \pm 0.44$ \\
\hline $\mathrm{ZC} 2$ & $150.4 \pm 2$ & $4.0 \pm 0.6$ & 0.54 & $3.3 \pm 0.05$ & $97.45 \pm 0.75$ \\
\hline $\mathrm{ZC} 3$ & $149.6 \pm 1$ & $4.4 \pm 0.5$ & 0.51 & $3.1 \pm 0.03$ & $98.34 \pm 0.92$ \\
\hline ZC4 & $149.6 \pm 2$ & $4.5 \pm 0.4$ & 0.55 & $3.4 \pm 0.04$ & $99.87 \pm 0.72$ \\
\hline ZC5 & $151.4 \pm 2$ & $4.4 \pm 0.6$ & 0.56 & $3.2 \pm 0.07$ & $99.14 \pm 0.37$ \\
\hline ZC6 & $150.7 \pm 2$ & $4.2 \pm 0.1$ & 0.45 & $3.4 \pm 0.05$ & $97.56 \pm 0.25$ \\
\hline ZC7 & $148.95 \pm 1$ & $4.2 \pm 0.3$ & 0.45 & $3.1 \pm 0.03$ & $98.3 \pm 0.49$ \\
\hline ZC8 & $149.15 \pm 1$ & $4.7 \pm 0.2$ & 0.54 & $3.2 \pm 0.04$ & $99.3 \pm 0.33$ \\
\hline ZC9 & $150.26 \pm 2$ & $4.2 \pm 0.3$ & 0.55 & $3.3 \pm 0.02$ & $98.2 \pm 0.47$ \\
\hline ZC10 & $150.36 \pm 2$ & $4.0 \pm 0.6$ & 0.56 & $3.5 \pm 0.05$ & $99.2 \pm 0.65$ \\
\hline ZC11 & $149.25 \pm 3$ & $4.2 \pm 0.1$ & 0.48 & $3.1 \pm 0.06$ & $99.3 \pm 0.55$ \\
\hline ZC12 & $148.26 \pm 1$ & $4.1 \pm 0.5$ & 0.45 & $3.2 \pm 0.07$ & $97.2 \pm 0.45$ \\
\hline ZC13 & $150.5 \pm 1$ & $4.3 \pm 0.2$ & 0.51 & $3.3 \pm 0.09$ & $102.3 \pm 1.50$ \\
\hline ZC14 & $150.63 \pm 1$ & $4.4 \pm 0.7$ & 0.52 & $3.3 \pm 0.04$ & $103.5 \pm 1.00$ \\
\hline ZC15 & $151.85 \pm 1$ & $4.5 \pm 0.2$ & 0.53 & $3.4 \pm 0.05$ & $103.0 \pm 0.92$ \\
\hline
\end{tabular}

Each value represents the mean \pm SD $(n=3)$

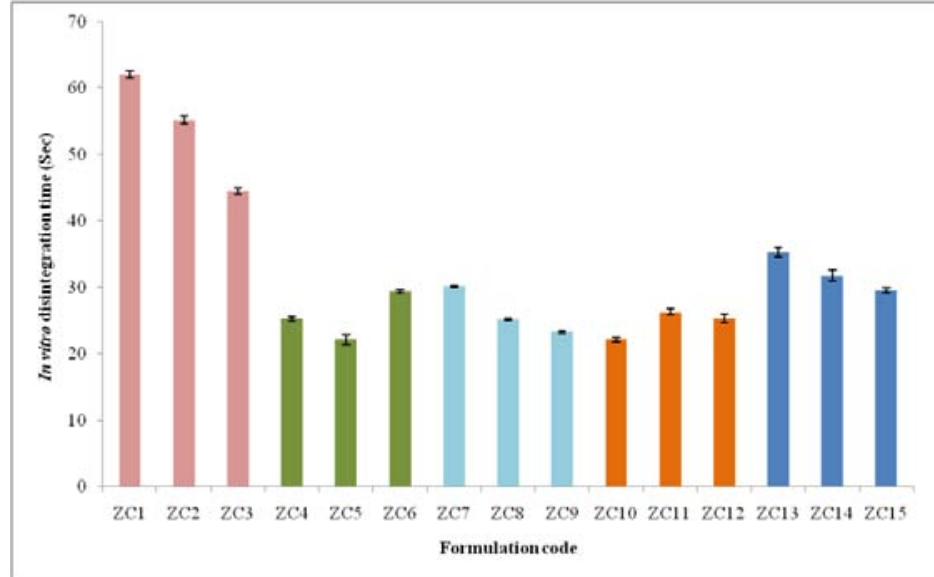

Fig. 3: In vitro disintegration time graph of core tablets, each value represents the mean $\pm \operatorname{SD}(n=3)$ 
The disintegration time of the tablets was determined as per the Indian Pharmacopoeia monograph. The test was carried out using the Tablet disintegration apparatus. For ZC5 formulation was found to be $22.13 \pm 0.72$ seconds very less disintegration time compared to other formulation. ZC5 formulation contained $16 \mathrm{mg}$ natural super disintegrant locust bean gum because of the appreciable capability of locust bean gum to increase water penetration due to wicking action which increases porosity thus lowers disintegration time [38].

\section{In vitro drug release studies}

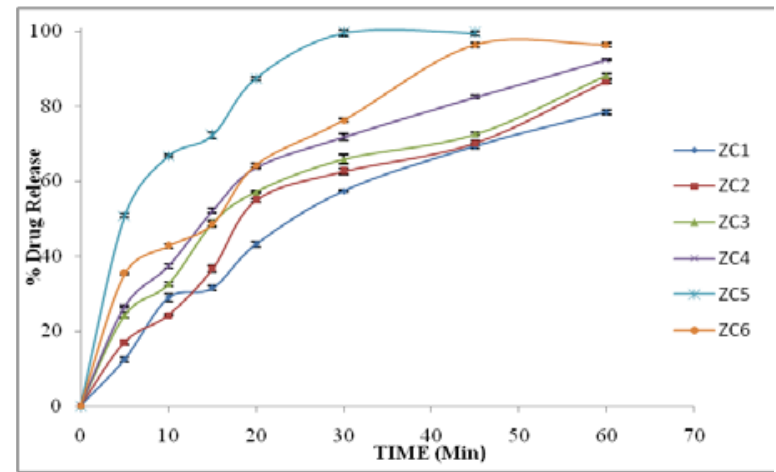

Fig. 4: Dissolution graph of core tablets using natural super disintegrants i.e., Plantago ovata seed powder, locust bean gum, each value represents the mean $\pm S D(n=3)$

Core tablets of Zafirlukast were prepared by direct compression technique using two different classes of super-disintegrants, i.e., Naturals class (Locust bean gum, Plantago ovata seed powder) and synthetic class (SSG, CCS, CP). Overall formulation ZC5 containing Locust bean gum at $16 \mathrm{mg}$ disintegrated rapidly to release the drug. The formulations ZC5 were selected for dissolution studies based on their better and satisfactory evaluation studies parameter [39]. From the result, it was concluded that formulation ZC5 are found to be stable and retained their original properties.

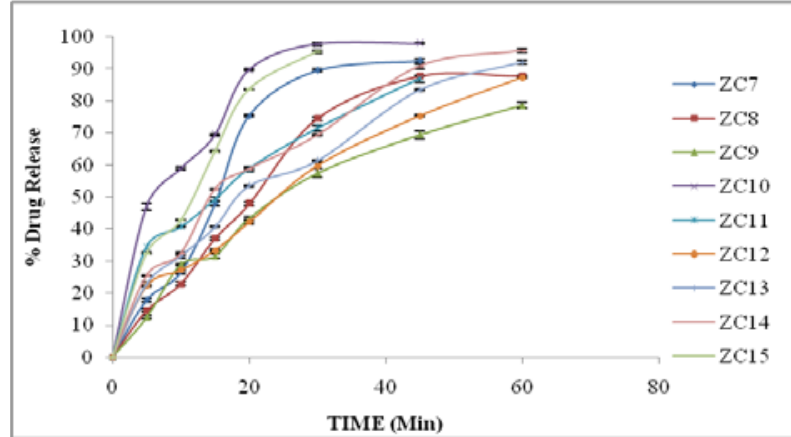

Fig. 5: Dissolution data of core tablets by using Synthetic super disintegrants i.e., Sodium starch glycolate (SSG), Crospovidone (CP), Cross carmellose sodium (CCS), each value represents the mean $\pm S D(n=3)$

The formulations $\mathrm{ZC5}$, ZC10 showed more than $50 \%$ of drug release within $10 \mathrm{~min}$ and almost $98 \%$ of the drug release in $30 \mathrm{~min}$. The rapid drug dissolution might be due to the easy breakdown of the particle by super disintegrant action [40]. ZC5 containing $16 \mathrm{mg}$ Locust bean gum and ZC10 containing $8 \mathrm{mg}$ Cross carmellose sodium (CCS) amount. From in vitro dissolution data, it was observed the maximum \% of Zafirlukast released in $30 \mathrm{~min}$. It was also observed that the change in concentration of both the super disintegrants Locust bean gum and croscarmellose sodium had a significant effect on the dissolution profile of Zafirlukast core tablets.

The excellent in vitro release profile is probably the solubility enhancement properties of Locust bean gum. At a stable hardness of tableting, the disintegration time is measured, it is found that the batch ZC5 shows minimum disintegration time (22.13 $\mathrm{min})$, this is attributes to the Locust bean gum capacity of depicting Swelling and Wicking both mechanism simultaneously. It accommodates a helping hand in obtaining burst release of the drug [41]. ZC5 also showed a better dissolution profile and complied with all other parameters with less variation in results and hence was selected as the optimized core tablet formulation.

Table 10: In vitro quality control parameters for coated tablets

\begin{tabular}{|c|c|c|c|c|c|}
\hline Formulation code & Average weight (mg) & Hardness $\left(\mathrm{kg} / \mathrm{cm}^{2}\right)$ & Friability (\% loss) & Thickness (mm) & Drug content (\%) \\
\hline P1 & $349.25 \pm 0.61$ & $5.9 \pm 0.15$ & 0.35 & $4.99 \pm 0.03$ & $99.45 \pm 0.55$ \\
\hline P2 & $350.65 \pm 0.80$ & $5.5 \pm 0.20$ & 0.29 & $4.89 \pm 0.06$ & $99.86 \pm 0.33$ \\
\hline P3 & $350.89 \pm 0.65$ & $5.8 \pm 0.55$ & 0.51 & $4.68 \pm 0.05$ & $99.73 \pm 0.45$ \\
\hline P4 & $350.77 \pm 0.55$ & $5.3 \pm 0.50$ & 0.48 & $4.90 \pm 0.06$ & $99.92 \pm 0.64$ \\
\hline P5 & $348.99 \pm 0.75$ & $5.2 \pm 0.22$ & 0.63 & $4.19 \pm 0.07$ & $99.65 \pm 0.12$ \\
\hline P6 & $350.12 \pm 0.71$ & $5.1 \pm 0.56$ & 0.81 & $4.72 \pm 0.08$ & $99.55 \pm 0.23$ \\
\hline P7 & $347.35 \pm 0.80$ & $5.3 \pm 0.23$ & 0.15 & $4.39 \pm 0.07$ & $98.42 \pm 0.37$ \\
\hline P8 & $348.46 \pm 0.82$ & $5.8 \pm 0.12$ & 0.43 & $4.57 \pm 0.05$ & $99.85 \pm 0.49$ \\
\hline P9 & $349.14 \pm 1.01$ & $5.1 \pm 0.27$ & 0.57 & $4.38 \pm 0.04$ & $99.12 \pm 0.57$ \\
\hline P10 & $350.32 \pm 0.64$ & $5.0 \pm 0.45$ & 0.43 & $4.29 \pm 0.03$ & $98.42 \pm 0.62$ \\
\hline $\mathrm{P} 11$ & $352.47 \pm 0.71$ & $5.94 \pm 0.37$ & 0.37 & $4.35 \pm 0.01$ & $99.65 \pm 0.19$ \\
\hline
\end{tabular}

Each value represents the mean $\pm \mathrm{SD}(\mathrm{n}=3)$, All the parameters for press coated tablets such as weight variation, friability, hardness, thickness, drug content were found to be within limits.

In vitro dissolution of the matrix, Zafirlukast coated tablets containing HPMC of various viscosities. The Prepared tablets did not disintegrate, however, a gel layer was formed on the surface of the tablet due to swelling of HPMC in presence of water. Here the concentration of each type of HPMC (K4M and K100M) was kept at 62.5 mg. Formulations containing HPMC K100M showed delayed release as compared to others. HPMC K100M tablets exhibited a significant effect on drug release, it is due to more viscosity and high molecular weight of HPMC K100M in addition to its slower rate of erosion and more swelling. HPMC (K4M and K100M) with hydrophobic polymers like Ethyl cellulose (EC), Eudragit RS100, and Eudragit RL100 for the drug release was retarded with HPMC K4 M in the concentration of 1:1 (Hydrophobic polymer: hydrophilic polymer) up to $97.88 \%$ drug released in $12 \mathrm{~h}$. The overall drug release is affected by the rate of water uptake and diffusion rate of the drug through the swollen gel being formed. This gel increases the diffusion path length of the drug. Its viscous nature also affects the diffusion coefficient of the drug [42]. As a result, a reduction in the drug release rate is obtained. Drug release from HPMC matrices showed that the viscosity of polymer plays important role in the retardation of drug release as

\section{HPMC K100M>HPMC K4M}

Drug release studies were observed in the case of Ethylcellulose and combination with various viscosity grades of HPMC like K4M and $\mathrm{K} 100 \mathrm{M}$. But hydrophobic and hydrophilic polymer ratio 1:1 for all 
the formulations. EC was incorporated in the hydrophilic matrix; the matrix could release the drug retarded more up to $12 \mathrm{~h}$ only. Incorporation of EC was found to control the drug release to some extent, which could be attributed to the decreased penetration of the solvent molecules, in the presence of hydrophobic polymer leading to decreased diffusion of the drug from the matrix.

Hydrophobic polymers, which are capable of forming insoluble or skeleton matrices, have been widely used for controlling the release of drugs due to their inertness and drug embedding ability [43]. Liquid penetration into the matrix is a rate-controlling step in such systems unless channeling agents are used, for Example: Eudragit RS100 and Eudragit RL 100 .

Eudragits (polymethyl methacrylates) are extensively used as release controlling agents. The drug release was slow down in Eudragit RS100 than in Eudragit RL100 due to 5\% of functional quaternary ammonium groups present in Eudragit RS 100 and it was low permeability and $\mathrm{pH}$-independent but in the case of Eudragit RL 100 presence of $10 \%$ of functional quaternary ammonium groups, high permeability and $\mathrm{pH}$-independent.
During the dissolution process, it was observed that the hydrophilic polymer in the tablets resulted in a reduction in the drug release rate, all the tablets showed swelling the extent of swelling increased.

Drug release from hydrophobic matrices showed that the type of polymers plays an important role.

Retardation of drug release was in the order of

\section{EC>Eudragit RS 100>Eudragit RL 100}

Finally concluded that the P8 formulation containing Eudragit RS 100 and HPMC K4M in combination, was the best. This formulation was retarding the drug release $98.86 \%$ up to desired period (12 h).

\section{Release kinetics}

Data of in vitro release studies of formulations that were showing better drug release were fit into different equations to explain the release kinetics of Zafirlukast release from press coated tablets (P8). The data were fitted into various kinetic models such as Zero, Firstorder kinetics, Higuchi, Korsmeyer Peppas mechanisms, and the results were shown in the below figures.

Table 11: Dissolution data of press coated tablets using hydrophilic, hydrophobic polymers and combination

\begin{tabular}{|c|c|c|c|c|c|c|c|c|c|c|c|}
\hline Time (min) & P1 & P2 & P3 & P4 & P5 & P6 & P7 & P8 & P9 & P10 & P11 \\
\hline \multirow[t]{2}{*}{0} & $0.00 \pm 0$ & $0.00 \pm 0$ & $0.00 \pm 0$ & $0.00 \pm 0$ & $0.00 \pm 0$ & $0.00 \pm 0.0$ & $0.00 \pm 0.0$ & $0.00 \pm 0.0$ & $0.00 \pm 0.0$ & $0.00 \pm 0.0$ & $0.00 \pm 0.0$ \\
\hline & .00 & .00 & .00 & 00 & 00 & 0 & 0 & 0 & 0 & 0 & 0 \\
\hline \multirow[t]{2}{*}{$30(0.5 \mathrm{~h})$} & $0.00 \pm 0$ & $0.00 \pm 0$ & $0.00 \pm 0$ & $33.42 \pm 0$ & $21.80 \pm$ & $0.56 \pm 0.0$ & $0.12 \pm 0.0$ & $0.34 \pm 0.0$ & $0.46 \pm 0.0$ & $0.31 \pm 0.0$ & $0.14 \pm 0.0$ \\
\hline & .00 & .00 & .00 & .69 & 0.10 & 2 & 9 & 6 & 1 & 8 & 6 \\
\hline \multirow[t]{2}{*}{$60(1 \mathrm{~h})$} & $0.00 \pm 0$ & $0.00 \pm 0$ & $0.00 \pm 0$ & $41.86 \pm 0$ & $30.92 \pm$ & $0.77 \pm 0.0$ & $0.35 \pm 0.0$ & $0.61 \pm 0.0$ & $0.95 \pm 0.0$ & $0.55 \pm 0.1$ & $0.22 \pm 0.1$ \\
\hline & .00 & .00 & .00 & .37 & 0.45 & & 8 & 2 & 7 & 5 & 1 \\
\hline \multirow[t]{2}{*}{$120(2 \mathrm{~h})$} & $5.81 \pm 0$ & $10.89 \pm$ & $0.00 \pm 0$ & $50.33 \pm 0$ & $36.84 \pm$ & $1.21 \pm 0.3$ & $0.51 \pm 0.0$ & $2.34 \pm 0.1$ & $1.41 \pm 0.1$ & $0.82 \pm 0.2$ & $0.58 \pm 0.1$ \\
\hline & .31 & 0.65 & .00 & .81 & 0.88 & 9 & 5 & 5 & 0 & 3 & 2 \\
\hline \multirow[t]{2}{*}{$180(3 \mathrm{~h})$} & $12.34 \pm$ & $22.31 \pm$ & $22.14 \pm$ & $63.49 \pm 0$ & $39.28 \pm$ & $3.46 \pm 0.3$ & $0.62 \pm 0.2$ & $4.73 \pm 0.8$ & $4.45 \pm 0.1$ & $1.36 \pm 0.7$ & $1.12 \pm 0.2$ \\
\hline & 0.40 & 0.39 & 0.81 & .14 & 0.65 & 6 & 2 & 8 & 1 & 7 & 1 \\
\hline \multirow[t]{2}{*}{$240(4 \mathrm{~h})$} & $17.87 \pm$ & $35.35 \pm$ & $26.43 \pm$ & $73.81 \pm 0$ & $48.39 \pm$ & $39.54 \pm 0$ & $0.78 \pm 0.3$ & $37.48 \pm 0$. & $24.75 \pm 0$ & $1.81 \pm 0.4$ & $3.65 \pm 0.2$ \\
\hline & 0.34 & 0.67 & 0.41 & .84 & 0.44 & 10 & 5 & 75 & 39 & 3 & 4 \\
\hline \multirow[t]{2}{*}{$300(5 \mathrm{~h})$} & $22.89 \pm$ & $47.26 \pm$ & $38.18 \pm$ & $85.44 \pm 0$ & $55.83 \pm$ & $43.15 \pm 0$ & $1.95 \pm 1.0$ & $44.85 \pm 0$ & $42.27 \pm 0$ & $5.45 \pm 0.4$ & $7.34 \pm 0.2$ \\
\hline & 0.37 & 0.59 & 0.65 & .71 & 0.69 & 60 & & 45 & 55 & 5 & 7 \\
\hline \multirow[t]{2}{*}{$360(6 \mathrm{~h})$} & $31.83 \pm$ & $58.18 \pm$ & $42.27 \pm$ & $96.65 \pm 0$ & $65.66 \pm$ & $49.89 \pm 0$ & $46.34 \pm 0$ & $52.44 \pm 0$ & $48.54 \pm 0$ & $43.90 \pm 0$ & $12.16 \pm 0$. \\
\hline & 0.12 & 0.14 & 0.73 & .31 & 0.48 & 84 & 06 & 33 & 80 & 36 & 29 \\
\hline \multirow[t]{2}{*}{$420(7 \mathrm{~h})$} & $39.35 \pm$ & $63.48 \pm$ & $48.54 \pm$ & & $85.72 \pm$ & $52.77 \pm 0$ & $99.48 \pm 1$ & $63.19 \pm 0$ & $51.74 \pm 0$ & $65.32 \pm 0$ & $50.65 \pm 0$ \\
\hline & 0.92 & 0.79 & 0.14 & & 0.54 & 98 & 2 & 45 & 98 & 82 & 33 \\
\hline \multirow[t]{2}{*}{$480(8 \mathrm{~h})$} & $46.95 \pm$ & $77.34 \pm$ & $53.78 \pm$ & & $94.80 \pm$ & $58.04 \pm 0$ & & $74.55 \pm 0$ & $55.68 \pm 0$ & $98.45 \pm 1$ & $98.54 \pm 0$. \\
\hline & 0.14 & 0.52 & 0.43 & & 0.21 & 44 & & 06 & 58 & 01 & 39 \\
\hline \multirow[t]{2}{*}{$540(9 \mathrm{~h})$} & $51.89 \pm$ & $89.89 \pm$ & $55.68 \pm$ & & & $61.04 \pm 0$ & & $83.62 \pm 0$ & $62.14 \pm 0$ & & \\
\hline & 0.10 & 0.91 & 0.15 & & & 40 & & 40 & 51 & & \\
\hline \multirow[t]{2}{*}{$600(10 \mathrm{~h})$} & $65.34 \pm$ & $89.92 \pm$ & $67.35 \pm$ & & & $68.22 \pm 0$ & & $87.69 \pm 0$ & $67.35 \pm 0$ & & \\
\hline & 0.34 & 0.50 & 0.61 & & & 93 & & 71 & 92 & & \\
\hline \multirow[t]{2}{*}{$660(11 \mathrm{~h})$} & $76.62 \pm$ & & $73.62 \pm$ & & & $81.09 \pm 0$ & & $92.34 \pm 0$ & $76.43 \pm 0$ & & \\
\hline & 0.58 & & 0.46 & & & 13 & & 89 & 55 & & \\
\hline \multirow[t]{2}{*}{$720(12 \mathrm{~h})$} & $89.32 \pm$ & & $86.43 \pm$ & & & $89.03 \pm 0$ & & $98.86 \pm 0$ & $83.28 \pm 0$ & & \\
\hline & 0.26 & & 0.91 & & & 20 & & 56 & 29 & & \\
\hline
\end{tabular}

Each value represents the mean $\pm S D(n=3)$

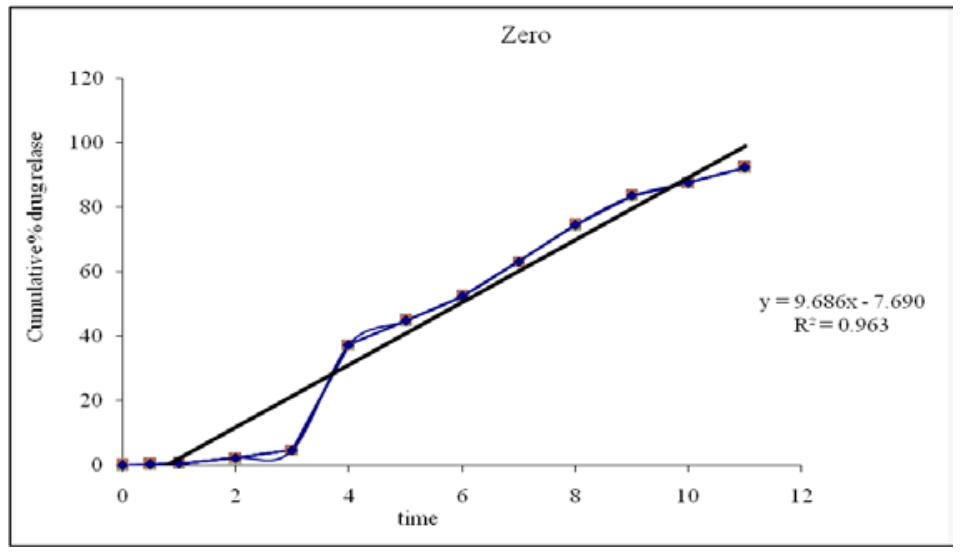

Fig. 6: Zero-order plot of optimized formulation 


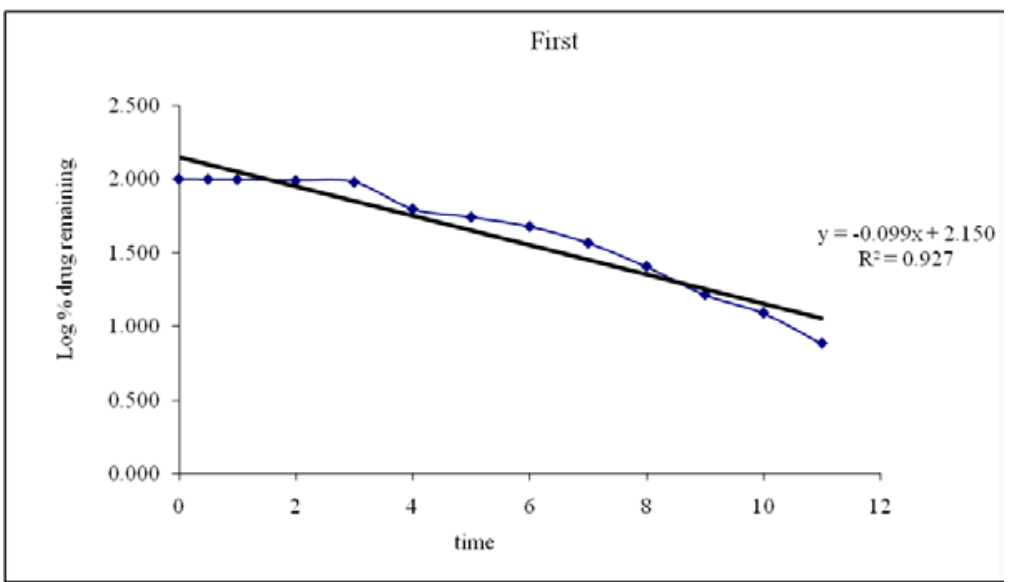

Fig. 7: First-order plot of optimized formulation

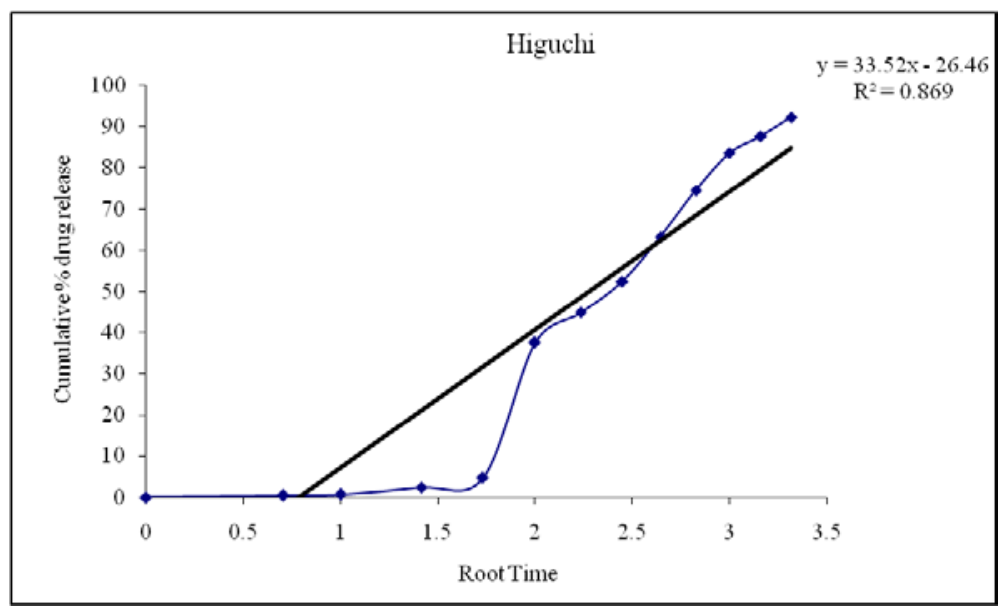

Fig. 8: Higuchi plot of optimized formulation

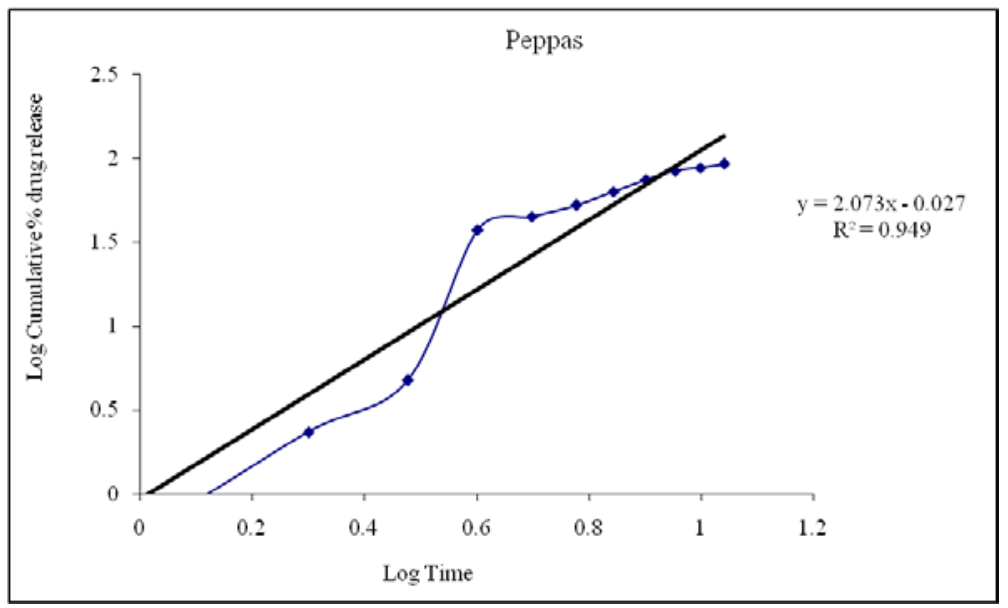

Fig. 9: Koresmeyer-peppas plot of optimized formulation

Based on all studies P8 formulation was found to be better when compared with all other formulations. This formulation was following a Zero-order mechanism with a regression value of 0.963 . The kinetics of zero-order release describes the release of drugs slowly and always constant over time. Increased drug concentration is directly proportional to time [44].

\section{Accelerated stability studies}

The stability study of the optimized Zafirlukast pulsatile tablets (P8) was carried out according to ICH guidelines at $40 \pm 2{ }^{\circ} \mathrm{C} / 75 \pm 5 \% \mathrm{RH}$ for three months by storing the samples in (Lab-care, Mumbai) stability chamber [45]. The results from stability studies are shown in the figure. 


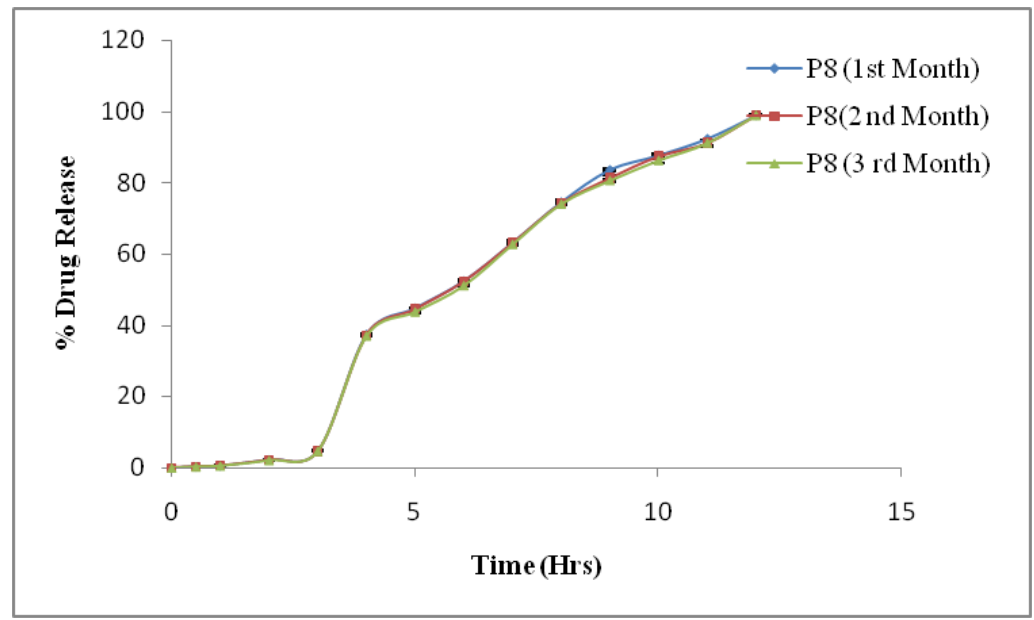

Fig. 10: Stability dissolution profile of optimized Zafirlukast pulsatile tablets (P8) for $1^{\text {st }}, 2^{\text {nd }}$ and $3^{\text {rd }}$ months, Each value represents the mean $\pm \operatorname{SD}(n=3)$

Table 12: Most satisfactory formulation during stability studies for optimized formulation

\begin{tabular}{ll}
\hline Time period (month) & Drug content $(\%)$ \\
\hline 1 & $99.85 \pm 0.09$ \\
2 & $99.85 \pm 0.07$ \\
3 & $99.84 \pm 0.10$ \\
\hline
\end{tabular}

Each value represents the mean $\pm \operatorname{SD}(n=3)$

There was no major change in the various physicochemical parameters evaluated drug content, in vitro drug release pattern at the various sampling points. There was no statistically significant difference between the initial values and the results obtained during stability studies.

Zafirlukast pulsatile tablets showed no significant change in the physical appearance, percent drug content, In vitro, drug release studies were determined at 1st Month, 2nd month, 3 rd Month which showed no significant change at room temperature and instability chamber at $40 \pm 1{ }^{\circ} \mathrm{C}$ and $75 \%$ relative humidity this indicates that optimized formulations were stable [46].

\section{In vivo studies-pharmacokinetic studies}

All the pharmacokinetics parameters are displayed in Table. Meantime to reach peak drug concentration (Tmax) was $1.58 \mathrm{~h}$, while the mean maximum drug concentration (Cmax) was 503.1 $\mathrm{ng} / \mathrm{ml}$. The values for Cmax, Tmax, AUC were found to be comparable indicating that their rapid and transient release of a certain amount of drug within a short period immediately after a predetermined off-release period patterns were similar.

Table 13: Pharmacokinetic parameters of optimized formulation

\begin{tabular}{lll}
\hline S. No. & Parameter & Zafirlukast optimized pulsatile tablets \\
\hline 1 & $\mathrm{C}_{\max }$ & $503.1 \mathrm{ng} / \mathrm{ml}( \pm 0.21)$ \\
2 & $\mathrm{~T}_{\max }(\mathrm{hr})$ & $1.58 \mathrm{~h}( \pm 0.57)$ \\
3 & $\mathrm{AUC}$ & $1342.8 \mathrm{ng} / \mathrm{l} \cdot \mathrm{h}( \pm 1.29)$ \\
\hline
\end{tabular}

\section{CONCLUSION}

The pulsatile drug delivery system was developed successfully using the press coating technique. The present investigation revealed that the coating of the core tablet with $62.5 \mathrm{mg}$ of Eudragit RS100 and 80 mg HPMC K4M and $62.5 \mathrm{mg}$ HPMC K4M provided desired lag time required for chronotherapy of Asthma. The optimized formulation showed 4 h of pulsatile release lag time, and more drug release up to
$12 \mathrm{~h}$ of time. In vitro drug release study showed $98.86 \%$ drug release in $12 \mathrm{~h}$. Optimized formulation (P8) showed good stability at accelerated stability conditions. From the experimental findings, it can be concluded that pulsatile tablets of Zafirlukast can give efficient therapy by reducing dose and dosing frequency and provide chronotherapy for effective management of morning the surge of Asthma. Finally, it may be concluded that a pulsatile drug delivery system offers a valuable dosage form treatment of Asthma.

\section{ACKNOWLEDGEMENT}

The Authors are thankful to Sura Labs, Dilshukhnagar, Hyderabad for providing the necessary facilities for the research work.

\section{FUNDING}

Nil

\section{AUTHORS CONTRIBUTIONS}

N. Shiva Krishna has generated the research plan, prepared and revised the manuscript. Dr. B. Jayanthi and A. Madhukarhave given guidance and supervision to carry out this study.

\section{CONFLICT OF INTERESTS}

None

\section{REFERENCES}

1. Bussermar T, Otto L, Bodmier R. Pulsatile drug delivery system. Crit Rev Ther Drug Carrier Syst 2001;18:433-58.

2. Youan BC. Chronopharmaceutics: gimmick or clinically relevant approach to drug delivery. J Controlled Release 2004;98:337-53.

3. Chaudhari SP, Chauradhi PD, Mistry CJ, Patil MJ. The effect of core and coating composition on drug release from directly compressed time controlled-release tablets. Pharm Tech 2007;31:132-44.

4. MS Sokar, AS Hanafy, AH El-Kamel, SS El-Gamal. Pulsatile corein-cup valsartan tablet formulations: in vitro evaluation. Asian J Pharm Sci 2013;8:234-43.

5. Shidhaye S, Dhone A, Budhkar T. Technologies in pulsatile drug delivery system. Int J Adv Pharm Biol Sci 2012;1:438-45.

6. Dalvadia H, Patelb J. Chronpharmaceutics, pulsatile drug delivery system as the current trend. Asian J Pharm Sci 2010;5:204-30.

7. Efentakis M, Koligliati S, Vlachou M. Design and evaluation of a dry coated drug delivery system with an impermeable cup, swellable top layer, and pulsatile release. Int J Pharm 2006;311:147-56.

8. Shweta Arora, J Ali, Alka Ahuja, Sanjula Baboota, J Qureshi. Pulsatile drug delivery systems: an approach for controlled drug delivery. Indian J Pharm Sci 2006;68:295-300.

9. Gaurav Thakur, Shahid Ud Din Wani, Surya Prakash Gautam. A review on recent advancement in pulsatile drug delivery systems. Int J Curr Pharm Res 2021;13:6-10. 
10. Pasham Sowmya, Venkatesh DP, Sujit Nayek. Pulsatile drug delivery system: a formulation approach for treatment of diseases. Int J Curr Pharm Res 2020;12:16-21.

11. Martin RJ, Schlegel SB. Chrono biology of Asthma. Am J Respir Crit Care Med 1998;158:1002-7.

12. Kulkarni PA, Jaiswal M, Jawale SB, Shirolkar SV, Kasture PV. Development and evaluation of press-coated tablets for chronopharmaceutical drug delivery using gellable and permeable polymers. Der Pharm Lett 2010;2:482-97.

13. Seshasayan A, Sreenivasa RB, Prasanna R, Ramana Murthy KV. Studies on the release of rifampicin from modified pulsincap technique. Indian J Pharma Sci 2001;1:337-9.

14. Swati C Jagdale, Vishnu M Suryawanshi, Sudhir V Pandya, Bhanudas S Kuchekar, Aniruddha R Chabukswar. Development of press-coated, floating-pulsatile drug delivery of lisinopril. Sci Pharm 2014;82:423-40.

15. Himabindu Peddapalli, Vasudha Bakshi, Narender Boggula. Formulation, in vitro and ex vivo characterization of mucoadhesive buccal tablets for an antihypertensive drug. Asian J Pharm Clin Res 2018;11:402-11.

16. Sreekanth K, Naresh G, Md Imran, Nagesh K, Hindustan Abdul Ahad. Design, development, and optimization of zafirlukast press coat tablets for pulsatile drug delivery. Int J Med Pharm Res 2014;2:834-41.

17. Soad A Yehia, Ahmed H Elshafeey, Aliaa ElMeshad, Hamoud A, Al-Bialey. A pharmaceutical study on different approaches for itopride hydrochloride sustainment: in vitro and in vivo evaluation. J Chem Pharm 2012;4:1398-412.

18. Sarada Anepu, Lohithasu Duppala, Soma Sundari M. Formulation development, characterization, and in vitro evaluation of floating matrix dosage form of Tramadol hydrochloride using various polymers. Asian J Pharm Clin Res 2017;10:281-90.

19. Hrishav Das Purkayastha, Bipul Nath. Formulation and evaluation of oral fast disintegrating tablet of Ibuprofen using two super disintegrants. Int J Curr Pharm Res 2017;9:92-5.

20. Ahmed E Aboutaleb, Sayed I Abdel-Rahman, Mahrous O Ahmed, Mahmoud A Younis. Design and evaluation of domperidone sublingual tablets. Int J Pharm Pharm Sci 2016;8:195-201.

21. Negar Bashardoust Josephine Leno Jenita, Parvin Zakeri Milani. Preparation, and in vitro investigation of chitosan compressed tablets for colon targeting. Adv Pharm Bull 2011;1:87-92.

22. Inder Kumar, Vinay Pandit. Cefpodoxime proxetil fast dissolving tablets: a comparative study. Int J Pharm Pharm Sci 2020;12:35-41.

23. Vishal Yadav, Prakash Jadhav, Pranali Salunkhe, Priti Nikam, Shital Matkar. Formulation and evaluation of gastroretentive tablets of antiulcer drug. Asian J Pharm Clin Res 2016;9:48-52.

24. Ayesha Salma Habeeb, Shahidulla SM. Formulation and in vitro evaluation of captopril floating tablets by using natural polymers. Pharm Innov 2018;7:82-9.

25. Poojari Anusha, Singaram Mounika, Adukondalu Devandla. Preparation and evaluation of gastroretentive floating tablets of enalapril maleate. Int J Pharm Biol Sci 2017;7:136-42.

26. Amrita Chakravorty, Mainak Chakraborty, Biswanath SA Factors influencing delayed-release followed by rapid pulse release of drugs from compression coated tablets for colon targeting. Int J Pharm Pharm Sci 2016;8:330-6.

27. Prasanth VV, Mitesh P Modi, Sam T Mathew, Abin Abraham. Formulation, and evaluation of enteric coated time-release press coated tablets of theophylline for chronopharmacotherapy. Der Pharm Lett 2012;4:599-606.

28. G Ravi, P Subhash Chandra Bose, Valluru Ravi, Damineni Sarita, P Srikanth Reddy, Sandeep Kanna. Development and evaluation of oral controlled release tablets of oxybutynin using various polymers. Res J Pharm Tech 2020;13:3854-60.
29. SB Thirumalesh Naik, Kambham Venkateswarlu, KB Chandrasekhar. Formulation and in vitro evaluation of orodispersible tablets of olanzapine for the improvement of dissolution rate. J Chem Pharm 2016;8:177-81.

30. Ghosh T, Karki VS, Ghosh A, Kumar A, Hullatti. A novel corecoat chronotherapeutic technique for effective delivery of antihypertensive drug. Int J Appl Pharm 2018;10:92-9.

31. K Kavitha, RAM Jainaf Nachiya. Formulation and evaluation of furosemide tablets as gastro retentive dosage forms using various polymers. Int J Sci Res 2019;8:11-6.

32. Upendra Kulkarni, NG Raghavendra Rao, Basawaraj S Patil. Fabrication and evaluation of fast dissolving tablets of tizanidine hydrochloride by solid dispersion technique. Int J Pharm Sci Rev Res 2011;6:88-93.

33. Garima Joshi, Abhinesh Kumar, Krutika Sawant. Enhanced bioavailability and intestinal uptake of Gemcitabine HCl-loaded PLGA nanoparticles after oral delivery. Eur J Pharm Sci 2014;60:80-9

34. Montella S, Maglione M, De Stefano S. Update on leukotriene receptor antagonists in preschool children wheezing disorders. Ital J Pediatr 2012;38:2-9.

35. Esmat Zien El-Deen, Mamdouh Ghorab, Shadeed Gadand Heba Yassin. Effect of different polymers on the release of diclofenac sodium controlled release drug delivery system. Res Rev J Pharm Pharm Sci 2015;4:11-21.

36. Poreddy Srikanth Reddy, V Alagarsamy, P Subhah Chandra Bose, Damineni Sarita, V Sruthi. Development and evaluation of indapamide effervescent floating tablets using different HPMC grade polymers. Int J Pharm Sci Rev Res 2019;57:122-9.

37. P Gopalakrishna, B Ramarao, G Chiranjeevi, Ramya Sri S. In vitro evaluation of gastro retentive floating drug delivery system for nitrendipine bilayer tablets. Int J Pharm Chem Res 2016;2:63-72.

38. Karan Malik, Gurpreet Arora, Inderbir Singh. Locust bean gum as super disintegrant-formulation and evaluation of nimesulide orodispersible tablets. Polimeryw Med 2011;41:17-28.

39. R Krishna Kumari, P Bharathi, CH Saritha Reddy. Formulation, in vitro drug release, and stability studies of clopidogrel rapidly disintegrating Asian J Res Pharm Sci Biotechnol 2013;1:40-54.

40. Anupam K Sachan, Ankita Gupta, Lovi Nigam, Ranjana Sharma, Sudhir S Gangwar. Design and characterization of solid dispersion-based fast dissolving tablet of cetirizine hydrochloride. MIT Int J Pharm Sci 2015;1:37-44.

41. N Kanaka Durga Devi, B Sai Mrudula, A Prameela Rani Chronomodulated drug delivery system of montelukast sodium. Der Pharm Lett 2010;2:316-29.

42. Sapna N Makhija, Pradeep R Vavia. Once-daily sustainedrelease tablets of venlafaxine, a novel antidepressant. Eur J Pharm Biopharm 2002;54:9-15.

43. Katayoun Derakhshandeh, Marzieh Soleymani. Formulation and in vitro evaluation of nifedipine controlled release tablet: influence of a combination of hydrophilic and hydrophobic matrix forms. Asian J Pharm 2010;4:185-93.

44. Anisa Amalia, Yudi Srifiana, Amalia Anwar. Physical properties and rate of diffusion transethosome curcumin using a combination of tween 60 and span 60 as surfactant. Int J Appl Pharm 2021;13:66-70.

45. Sandhya Rajendra Shenoy, Pritam Jain, Madhur Kulkarni. Development and evaluation of chronomodulated delivery system of metoclopramide hydrochloride. Int J Appl Pharm 2016;8:38-42.

46. Srividya Ramreddy, Prabhakar Kandadi, Kishan Veerabrahma. Formulation and pharmacokinetics of diclofenac lipid nanoemulsions for parenteral application. PDA J Pharm Sci Technol 2012;66:28-37. 